\title{
Overexpression of sorcin results in multidrug resistance in gastric cancer cells with up-regulation of P-gp
}

\author{
QINGCHUN HE ${ }^{1,2}$, GUIYING ZHANG ${ }^{2}$, DEFU HOU ${ }^{3}$, AIMING LENG $^{2}$, \\ MEIHUA XU ${ }^{2}$, JIE PENG $^{2}$ and TING LIU ${ }^{2}$ \\ Departments of ${ }^{1}$ Emergency, and ${ }^{2}$ Gastroenterology, Xiangya Hospital, and ${ }^{3}$ Cancer Research Institute, \\ Central South University, 87 Xiangya Road, Changsha 410008, Hunan Province, P.R. China
}

Received July 13, 2010; Accepted August 27, 2010

DOI: 10.3892/or_00001066

\begin{abstract}
Sorcin, a calcium-binding protein was found upregulated in the vincristine-induced multi-drug resistance (MDR) gastric cancer cell line SGC7901/VCR, over its parental SGC7901 cells in our previous proteomic studies. The present study explored the role and mechanism of sorcin in the development of MDR in gastric cancer. We constructed the recombinant plasmids FLAG-sorsin-pcDNA3.1 containing the full open reading frame of sorcin and a FLAG affinity tag. Overexpression of sorcin by gene transfection was able to confer drug resistance to vincristine, adriamycin, taxol and 5fluorouracil in SGC7901 cells.Down-regulation of sorcin expression by sorcin antisense oligonucleutides, (ASO) increased sensitivity to vincristine. The intracellular concentration of vincristine in SGC7901 cells decreased in sorcintransfected cells and increased in sorcin ASO-transfected cells, indicating that sorcin had a direct or indirect function on pumping the drug out of cells. Overexpression of sorcin up-regulated the expression of P-gp and P-gp inhibitor verapamil partially reversed the sorcin-mediated MDR in SGC7901 cell, suggesting that regulation of P-gp might be one of the mechanisms of sorcin-mediated MDR. The further study of the interaction protein of sorcin may be helpful for understanding the mechanisms of MDR in gastric cancer and developing possible strategies to treat gastric cancer.
\end{abstract}

Correspondence to: Dr Zhang Guiying, Department of Gastroenterology, Xiangya Hospital, Central South University, 87 Xiangya Road, Changsha 410008, Hunan Province, P.R. China E-mail: guiyingzhang@hotmail.com

Abbreviations: MDR, multidrug resistance; P-gp, P-glycoprotein; sorcin, obsoluble resistance-related calcium-binding protein; RTPCR, reverse transcriptase polymerase chain reaction; ASO, antisense oligonucleotide; VCR, vincristine; VRP, verapamil; ADM, adriamycin; 5-FU, 5-fluorouracil; HPLC, high performance liquid chromatography

Key words: sorcin, FLAG, multidrug resistance, P-glycoprotein, gastric cancer

\section{Introduction}

Gastric cancer mortality has declined dramatically around the world. Nonetheless, gastric cancer is still estimated to account for about $10 \%$ of invasive cancers worldwide and probably is likely to be the second leading cause of cancer death. High rates apply to Japan, China, Korea and Central and South America (1-4). Systemic chemotherapy is the major treatment for advanced gastric cancer, metastasis or recurrence after tumor resection. Multidrug resistance (MDR) is thought to be a major cause of failure in cancer chemotherapy. The acquisition of multidrug resistance in cancer cells is often associated with increased expression of ATPbinding cassette transporters, which protect cancer cells through the efflux of anti-cancer drugs, such as P-glycoprotein (P-gp) and MDR-associated protein (MRP1). However, inhibition of these pumps does not always result in the reversal of chemoresistance in patients (5). The absence of P-gp and MRP1 expression in some gastric cancer cases also indicates that there might be other mechanisms responsible for human gastric cancer MDR (6,7). Recently, research into the MDR of gastric cancer has revealed that, in addition to the classical ATP-binding cassette transporters, a number of other molecules might mediate the drug resistance of human gastric cancer $(8,9)$.

The multidrug-resistant gastric cancer cell line, SGC7901/ VCR, was derived from the human gastric cancer cell line SGC7901 by stepwise selection in vitro using vincristine (VCR) as an inducing reagent. It is a typical MDR cell line with overexpression of P-glycoprotein (10). However, treatment of SGC7901/VCR with verapamil (VRP), a potent inhibitor of P-glycoprotein, did not restore full sensitivity of these cells to VCR, which indicates that other mechanisms might be involved in the development of resistance to the drug and it is necessary to detect new protein related to chemoresistance (11). In our previous studies, chemoresistantrelated proteins of gastric cancer were screened by examining the differences of the overall protein expression pattern between SGC7901/VCR cells and its parent SGC7901 cells using proteomics approaches. The result showed that sorcin, or soluble resistance-related calcium-binding protein, was significantly overexpressed in SGC7901/VCR cells compare to their parent SGC7901 cells (12). The supression of sorcin expression by sorcin antisense oligonucleotides could enhance 
VCR chemosensitivity in SGC7901/VCR cells (13). These results suggested that high expression of sorcin was associated with chemoresistance of SGC7901/VCR.

Sorcin, a sytosolic protein of $22 \mathrm{kDa}$, which has 4 typical 'E-F hand' structures of calcium-binding site, was first identified in a VCR-resistant China hamster lung cell line by Meyers and Biedler (14), and was later demonstrated to be over-expression in several tumor cell types $(15,16)$ and many MDR cell lines $(17,18)$. Sorcin overexpression is associated with poor outcome in leukemia patients (19). Increased sorcin expression by gene transfer rendered ovarian and breast cancer cells resistant to Taxol (20). The role and contribution of sorcin overexpression in human gastric cancer MDR and the underlying mechanisms of sorcin in drug resistance, however, for most part remains elusive. The overexpression of sorcin genes may just be coincidental with the amplification of MDR (21). Other conflicting results suggested that sorcin might be independently involved in mediating MDR (22-24).

In the present study, we explored the role and mechanism of sorcin in the development of MDR in gastric cancer cells. The new findings may provide new clues to the mechanism of MDR and enable the selection of new candidates for targeting MDR in human gastric cancer.

\section{Materials and methods}

Vincristine-resistant gastric cancer cells (SGC7901/VCR) was a gift from Professor Fan Daiming from Xijing Hospital, Fourth Military Medical University. The human gastric cancer cell line SGC7901 was obtained from the Cancer Research Institute, Central South University. All cells were routinely cultured in RPMI-1640 (Gibco) supplemented with $10 \%$ fetal calf serum FCS in a $37^{\circ} \mathrm{C}$ humidified incubator with a mixture of $95 \%$ air and $5 \% \mathrm{CO}_{2}$. For SGC7901/VCR cells, the medium additionally contained $1.0 \mathrm{mg} / \mathrm{ml}$ vincristine to maintain its drug resistance phenotype. The eukaryotic expression vector pcDNA3.1-p53-FLAG and pcDNA3.1FLAG was generally provided by Dr Zeng Pingyao, Cancer Research Institute, Central South University.

Amplify and cloning of sorcin. Full-length sorcin cDNA was isolated and amplified from SGC7901/VCR cells by reverse transcriptase polymerase chain reaction (RT-PCR) utilizing primers that contained restriction sites $B g I I I$ and $X b a \mathrm{I}$. Oligonucleotide primers used for PCR were 5'-AAAAGATCT ATGGCGTACCGGGGCAT-3' and 5'-GGGTCTAGATTA AACACTCATGACACATTG- $3^{\prime}$, at the $5^{\prime}$ and $3^{\prime}$ termini of the translated region of the sorcin cDNA, respectively (25). The PCR procedure comprised: an initial step at $98^{\circ} \mathrm{C}$ for $1 \mathrm{~min}$ followed by 30 cycles of $98^{\circ} \mathrm{C}$ for $15 \mathrm{sec}, 68^{\circ} \mathrm{C}$ for $90 \mathrm{sec}$ and one last cycle at $68^{\circ} \mathrm{C}$ for $5 \mathrm{~min}$, using the Prime STAR HS DNA polymerase (Takara). The PCR products were electrophoresed on a $1.5 \%(\mathrm{w} / \mathrm{v})$ agorose gel and the sorcin fragment was purified using the Takara purification kit. The purified fragment was added with 5' linkage of poly(A) tail before ligate to the pGEM-T expression vector (Promega, Madison, WI). The ligation product, pGEM-T/ sorcin, was transform to the competent strain of JM109. The presence of recombinant plasmid was screened using blue-white screening and Amplicine. Transformants were screened for the proper insert by PCR and by exciting the inserted fragment with restriction enzymes $B g l I I$ and $X b a I$.

Construction of the FLAG-sorsin-pcDNA3.1 plasmid. pGEM-T DNA containing full-length of sorcin was isolated and was digested into discrete fragments with restriction enzymes $B g l I I$ and $X b a I$. The sorcin fragment was purified and was then rejoined into pcDNA3.1-p53-FLAG plasmid which was lineared and cut off p53 fragment by double digestion with the enzymes Bam $\mathrm{H} 1$ and $X b a \mathrm{I}$ (the cohesive end created by $B g l I I$ digestion is the same as that created by Bam H1 digestion. So, these two ends can be rejoined with DNA ligation), followed by sequence confirmation by DNA sequencing analysis (Takara).

Transfection of sorcin in SGC7901 cells. Cells were planted in 6-well plates. Twenty-four hours later, cells were transfected either with FLAG-pcDNA3.1 vector or FLAG-sorsin-pcDNA3.1 by mediation of Lipofectamine $2000^{\mathrm{TM}}$ (Invitrogen) according to the manufacturer's protocol. Forty-eight hours later, cells were placed in growth medium containing G418 (Gibco) $600 \mu \mathrm{g} / \mathrm{ml}$ for clone selection. After being cultured for 3-4 weeks, wells containing a single colony were chosen and propagated in growth medium containing G418 $200 \mu \mathrm{g} / \mathrm{ml}$.

RT-PCR analysis of sorcin expression. The transfected SGC7901 cells were screened for the expression of sorcin by RT-PCR using the primers mentioned as before or the primers include FLAG sequence: forward, 5'-ACTACAAG GACGACGATGA-3'; reverse, 5'-TACAGCAGCAAAGTA ACCA-3'. B-actin was used as an internal control: forward, 5'-CTACAATGAGCTGCGTGTGGC-3'; reverse, 5'-GAGG TCCAGACGCAGGATGGC-3'. Reverse transcription and PCR amplification were performed according to standard protocols (Sangon one-step RT-PCR kit). The PCR cycling conditions were 30 cycles of $94^{\circ} \mathrm{C}$ for $1 \mathrm{~min}, 58^{\circ} \mathrm{C}$ for $1 \mathrm{~min}$ and $72^{\circ} \mathrm{C}$ for $1 \mathrm{~min}$. PCR products were electrophoresed on a $1.5 \%$ agarose gel.

Western blot analysis of sorcin expression. The expression of sorcin protein in the established clones was monitored by Western blotting. Treated cells were scraped from the culture, washed twice with PBS, and incubated for $30 \mathrm{~min}$ on ice in lysis buffer (containing $150 \mathrm{mM} \mathrm{NaCl}, 50 \mathrm{mM}$ Tris, $1 \%$ Triton X-100, 0.1\% NP40,1 mM PMSF). After centrifugation at $16,000 \mathrm{x} \mathrm{g}$ for $15 \mathrm{~min}$ at $4^{\circ} \mathrm{C}$, supernatants were collected and the protein concentration in each was measured by the Bradford method. Aliquots of supernatants containing $50 \mu \mathrm{g}$ protein were boiled in SDS-reducing buffer for $5 \mathrm{~min}$, electrophoresed on $12 \%(\mathrm{w} / \mathrm{v})$ SDS-polyacrylamide gels, and transferred to nitrocellulose membranes. Membranes were blocked with 5\% non-fat dry milk, then probed with rabbit anti-FLAG antibody (Sigma) at a 1:1000 dilution in TBST buffer or goat anti-sorcin antibody (Santa Cruz Biotechnology, CA, USA) at a 1:200 dilution in TBST buffer for $2 \mathrm{~h}$ at room temperature, followed by incubation with peroxidase-conjugated anti-goat or anti-rabbit antibodies in TBST for additional $2 \mathrm{~h}$. Blots were developed with 

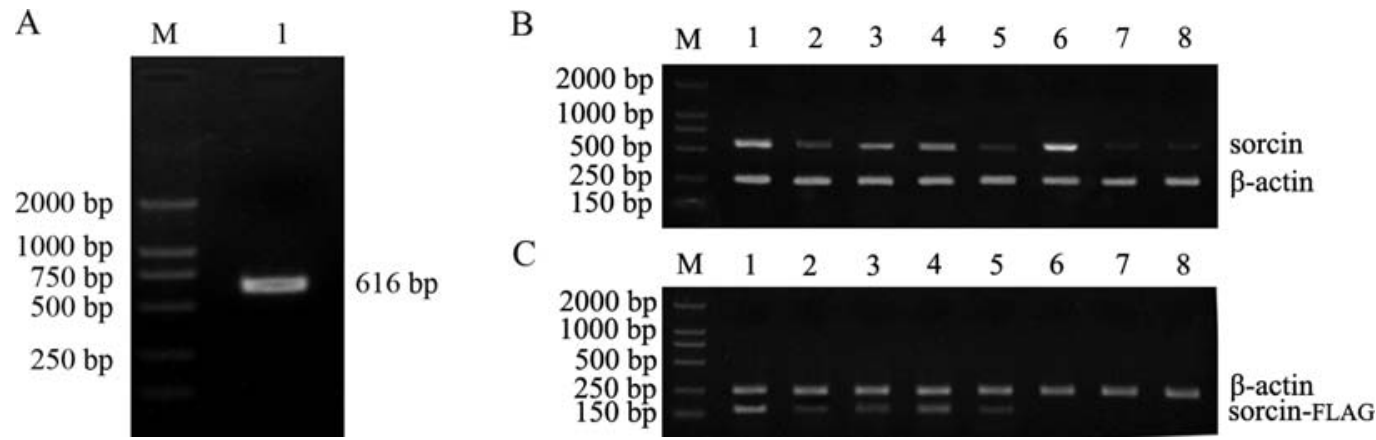

Figure 1. Overexpression of sorcin in SGC7901 cells. (A) Amplification of full-length sorcin cDNA from SGC7901/VCR cells by RT-PCR. M, DL2000 DNA marker; lane 1, sorcin gene. (B and C) RT-PCR analysis of the levels of sorcin and sorcin-FLAG expression in sorcin-FLAG-transfected SGCC7901 cells.

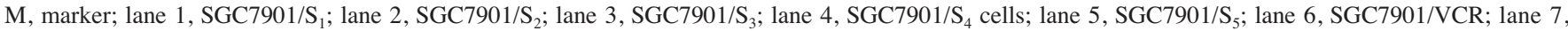
SGC7901-FLAG; lane 8, SGC7901.

Enhanced Chemiluminescence Plus reagent (Amersham, Arlington Heights, IL) according to the manufacturer's protocol. The experiment was repeated three times.

Drug sensitivity assay. The sensitivity of cells to each anticancer drug was determined using the tetrazolium dye assay. Cells $\left(8 \times 10^{3}\right.$ cells/well) were seeded in 96-well plates together with different concentrations of the test drug. The concentration ranges were $0.005-50 \mu \mathrm{g} / \mathrm{ml}$ for $\mathrm{VCR}, 0.004-40 \mu \mathrm{g} / \mathrm{ml}$ for adriamycin (ADM), $0.1-1000 \mu \mathrm{g} / \mathrm{ml}$ for 5-fluorouracil (5-FU) and $0.01-10 \mu \mathrm{g} / \mathrm{ml}$ for Taxol. After incubation at $37^{\circ} \mathrm{C}$ for $72 \mathrm{~h}, 20 \mu \mathrm{g}$ of $5 \mathrm{mg} / \mathrm{ml} \mathrm{3-(4,5-dimethylthiazol-2-yl)-}$ 2,5-diphenyltetrazolium bromide (MTT; Sigma) was added to each well. The cells were lysed after incubation for $4 \mathrm{~h}$ at $37^{\circ} \mathrm{C}$ by adding of $150 \mu \mathrm{l} \mathrm{DMSO} /$ well (2-propanol-0.1 N $\mathrm{HCl})$. The absorbance of the wells was then read at $490 \mathrm{~nm}$ using a spectrophometer (Bio-Tek, USA). The drug concentration that produced $50 \%$ inhibition of growth $\left(\mathrm{IC}_{50}\right)$ was estimated for each drug using the relative survival curves. Fold-resistance was defined as the $\mathrm{IC}_{50}$ value of the sorcintransfected clone/ $\mathrm{IC}_{50}$ of parent SGC7901 cells. To assess the reversal effect of VRP, cells were treated with VRP $(0,2.5$, $5,10 \mu \mathrm{g} / \mathrm{ml})$ together with VCR. The reversal effects of VRP were calculated as the $\mathrm{IC}_{50}$ value in the absence of VRP to that in the presence of VRP. Each study was performed in triplicate and repeated three times.

Supression of sorcin expression by sorcin antisense oligonucleotides. To verify the correlation of sorcin and MDR of gastric cancer, chemosensitivity assay was performed after sorcin expression was supressed by sorcin antisense oligonucleotides (ASO). The sequence of sorcin ASO was presented previously (13). It corresponded to the human sorcin translation initiation site 5'-TACGCCATGCTGCA GACTGC-3'. A scrambed ASO 5'-CAGCGCTGACAACAG TTTCAT-3' was used as a control. Phosphorothioate ASOs were synthesized by Takara. The sequence of the sorcin ASO and Scambled ASO was not found to be similar to any known sequence of the mammalian gene. The sorcin ASO and scrambled ASO were transfected into SGC7901 cells by mediation of Lipofectamine 2000 (Invitrogen) according to the manufacturer's protocol. Twenty-four hours later, cells were screened for the expression of sorcin by RT-PCR. The sensitivity of cells to VCR was determined using the tetrazolium dye assay.

HPLC analysis of intracellular concentration of VCR. Cells $\left(1 \times 10^{7} /\right.$ well) were exposed to VCR at a concentration of $1 \mathrm{mg} / \mathrm{l}$ in absence or presence of a concentation of $1 \mathrm{mg} / \mathrm{l}$ with a $5 \mathrm{mg} / \mathrm{l} \mathrm{VRP}$. After incubating at $37^{\circ} \mathrm{C}$ for $1 \mathrm{~h}$, the medium was sucked up and cells were quickly washed 3times in ice-cold phosphate-buffer (PBS). Each well was added with $0.5-\mathrm{ml}$ pure water, followed by freezing $\left(-20^{\circ} \mathrm{C}\right)$ and thawing for 3 times. The cells debris was pelleted by centrifugation at $10000 \mathrm{x} \mathrm{g}$ for $30 \mathrm{~min}$ at $4^{\circ} \mathrm{C}$ and the supernatant was used to determine the intra-cellular concentration of VCR by high performance liquid chromatography (HPLC).

Analysis of P-gp expression. The protein level of P-gp in sorcin transfected SGC7901 cells with or without sorcin ASO transfection and their parent SGC7901 cells were analyzed using Western blot analysis.

Statistical analysis. The significance of the data was determined by Student's t-test for all in vitro studies. $\mathrm{P}<0.05$ was deemed significant. All statistical analyses were done using SPSS software.

\section{Results}

Clone and overexpression of sorcin in SGC7901 cells. A 616 bp cDNA fragment was synthesized by PCR using mRNA of SGC7901/VCR cells as the initiation template (Fig. 1A), and subclone into the pGEM-T vector. The recombinant vector was screened by double digest with the enzyme $B g l \mathrm{II}$ and $X b a \mathrm{I}$. The sorcin fragment was excised from the pGEM-T vector by digestion with $B g l \mathrm{II}$ and $\mathrm{XbaI}$, and was ligated into FLAG-p53-pcDNA3. One plasmid had the p53 fragment cut off by double digestion with the enzymes $B a m \mathrm{H} 1$ and $\mathrm{XbaI}$. This created the expression plasmid FLAGsorsin-pcDNA3.1. DNA sequencing (Takara) confirmed that the cloned gene segment was $100 \%$ homologous to the published sorcin sequence (Genebank BC011025) and FLAG 
Table I. $\mathrm{IC}_{50}$ of anticancer drugs for gastric cancer cells $(\mu \mathrm{g} / \mathrm{ml})$.

\begin{tabular}{lcccc}
\hline Cell line & VCR & ADM & Taxol & 5-FU \\
\hline SGC-7901 & $0.48 \pm 0.07$ & $0.16 \pm 0.03$ & $0.09 \pm 0.01$ & $0.74 \pm 0.11$ \\
SGC7901-FLAG & $0.44 \pm 0.09$ & $0.17 \pm 0.05$ & $0.11 \pm 0.01$ & $0.85 \pm 0.13$ \\
SGC7901/S & $4.26 \pm 0.28^{\mathrm{a}}$ & $0.98 \pm 0.12^{\mathrm{a}}$ & $0.6 \pm 0.08^{\mathrm{a}}$ & $2.07 \pm 0.25^{\mathrm{b}}$ \\
SGC7901/VCR & $12.16 \pm 1.75^{\mathrm{a}}$ & $2.74 \pm 0.33^{\mathrm{a}}$ & $1.69 \pm 0.27^{\mathrm{a}}$ & $3.63 \pm 0.46^{\mathrm{a}}$ \\
\hline
\end{tabular}

Drugs sensitivity of sorcin-transfected SGC7901 cells and the control cells was determined by the MTT assay. The IC ${ }_{50}$ value (means \pm SD; defined as the concentration of drug required to kill $50 \%$ of the cells) were calculated using linear regression analysis. Data presented are means of three separate experiments, each performed in triplicate. ${ }^{\mathrm{P}}<0.01$, ${ }^{\mathrm{b}} \mathrm{P}<0.05$, vs. SGC7901 cells and SGC7901/FLAG cells. Transfection of sorcin induced 8.87-fold VCR resistance, 6.13-fold ADM resistance, 6.67-fold Taxol resistance and 2.80-fold 5-FU resistance. Fold-resistance was defined as the $\mathrm{IC}_{50}$ value of $\mathrm{SGC7901/ \textrm {S } _ { 1 } \text { cells/IC }}$ 50 value of parental SGC7901 cells.

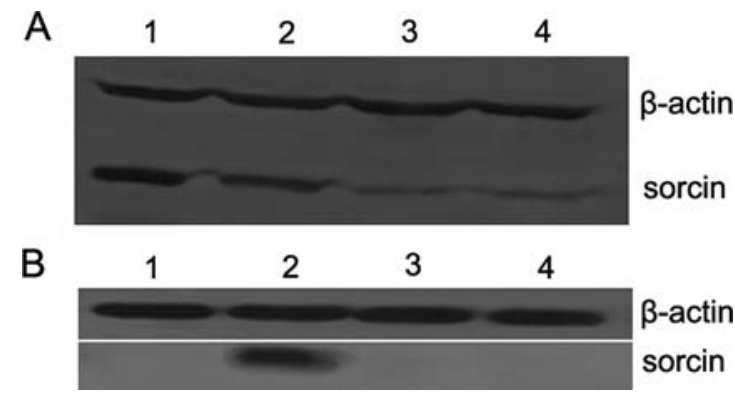

Figure 2. Overexpression of sorcin in sorcin-transfected cells detected by Western blot analysis. (A) Polyclonal antibody sorcin was used as primary antibody; (B) polyclonal antibody FLAG was used as primary antibody. ß-actin was used as an internal control. Lane 1, SGC7901/VCR; lane 2, SGC7901/S ${ }_{1}$; lane 3, SGC7901/FLAG; lane 4, SGC7901 cells.

sequence (Genebank DD271454). After transfection of SGC7901 cells with the FLAG-sorsin-pcDNA3.1 construct and subsequent G418 selection, individual clones were isolated and examined by RT-PCR for sorcin expression. All 5 randomly picked sorcin-transfected clones (SGC7901/S $\mathrm{S}_{1}$ SGC7901/S $\mathrm{S}_{5}$ ) yielded positive PCR sorcin product with expected size (Fig. 1B and C). The level of sorcin expression in these clones was much higher than the parent SGC7901 cells and SGC7901/S $\mathrm{S}_{1}$ yielding much stronger PCR signals than others, while the control FLAG-pCDNA3.1 plasmid did not change the sorcin expression in SGC7901 cells. The overexpression of sorcin in SGC7901/S 1 was confirmed by Western blot analysis (Fig. 2). Based on these observations, SGC7901/S 1 was selected for further experiments.

Overexpression of sorcin leads to MDR in SGC7901 cells. To investigate whether sorcin overexpression can produce VCR resistance and cross-resistant to other chemotherapeutic agents, MTT assay was initiated. The transfectant SGC7901/ $\mathrm{S}_{1}$ cells were subject to a growth inhibition assay in the presence of various concentrations of VCR, ADM, Toxal and 5-FU. As shown in the Table I, SGC7901/S 1 was found to be 8.87 -fold resistance to VCR, 6.13-fold ADM resistance, 6.67-fold Taxol resistance and 2.80-fold 5-FU resistance. As expected, the FLAG-pcDNA3.1 plasmid-transfected

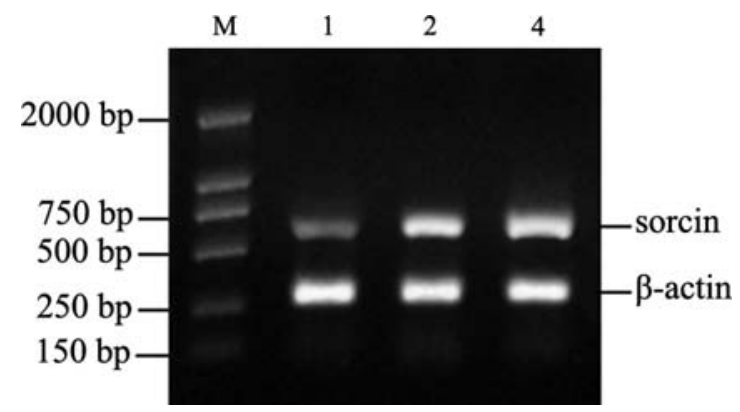

Figure 3. Inhibition of sorcin expression by sorcin-ASO. The levels of sorcin expression in sorcin-ASO transfected SGC7901/ $\mathrm{S}_{1}$ cells and the control cells were detected by RT-PCR. M, DL2000 DNA marker; lane 1,

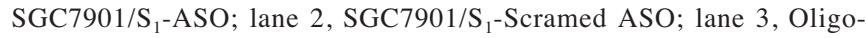
fectamine.

clone SGC7901/FLAG was equally sensitive to the drugs as the parent SGC7901 cells. All values are presented as the mean \pm SD ${ }^{\text {aP }}<0.01,{ }^{\text {b }} \mathrm{P}<0.05$, vs. SGC7901 cells and SGC7901/ FLAG cells.

Inhibition of sorcin expression by sorcin ASO leads to increased VCR-sensitivity in $S G C 7901 / S_{1}$ cells. Further studies were performed to dissect out the contribution

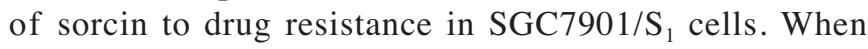
SGC7901 cells with overexpression of sorcin gene were transfected with sorcin ASO, the level of sorcin expression was decreased in comparison with the cells tranfected with srambled ASO and oligofectamine (Fig. 3). In the MTT assay the sorcin ASO transfected SGC7901/S 1 cells showed significantly decreased $\mathrm{IC}_{50}$ value $(1.3 \pm 0.11 \mu \mathrm{g} / \mathrm{ml})$ for VCR compared to the control cells $\left(\mathrm{IC}_{50 \text { srambled Aso }}\right.$ $4.17 \pm 0.26 \mu \mathrm{g} / \mathrm{ml}$ and $\left.\mathrm{IC}_{50 \text { oligofectamine }} 3.92 \pm 0.19 \mu \mathrm{g} / \mathrm{ml}\right)$. These data suggested that overexpression of sorcin promoted multidrug-resistant phenotype of gastric cancer cells.

Intracellular concentration of VCR. Because MDR of cancer is mainly due to alterations of drug influx and efflux, VCR intracellular concentration was explored. The HPLC analysis showed that compared with the parent SGC7901 cells, the concentration of VCR in SGC7901/S 
Table II. The intracellular concentration of VCR in SGC7901 cells $(\mathrm{ng} / \mathrm{ml})$.

\begin{tabular}{lllc}
\hline & SGC7901 & SGC7901/S $_{1}$ & SGC7901/S $_{1}$-ASO \\
\hline VCR & $94.10 \pm 4.24^{\mathrm{a}}$ & $21.75 \pm 2.38^{\mathrm{a}-\mathrm{c}}$ & $77.69 \pm 4.27^{\mathrm{c}}$ \\
VCR+VRP & $89.62 \pm 3.79$ & $74.23 \pm 4.51^{\mathrm{b}}$ & \\
\hline
\end{tabular}

The intracellular concentration of VCR in sorcin and sorcin-ASO transfected SGC7901 cells along with the parent SGC7901 cells was assessed by HPLC assay. All values are presented as mean \pm SD of three experiments. ${ }^{\text {a }}<0.01$ vs. SGC7901 cells and SGC7901/ $\mathrm{S}_{1}$ cells. ${ }^{\mathrm{b}} \mathrm{P}<0.01$ vs. treated with $\mathrm{VCR}$ and treated with VCR+VRP. ${ }^{c} \mathrm{P}<0.01$ vs. SGC7901/S 1 cells and SGC7901/S $\mathrm{S}_{1}$-ASO cells. Compared with the parent SGC7901 cells, the concentration of VCR in SGC7901/S 1 cells was $76.89 \%$ decreased, but when treated by verapamil, it increased 2.41-fold. And compared with the SGC7901/S 1 cells, the concentration of VCR in SGC7901/S $\mathrm{S}_{1}$-ASO cells was 2.57 -fold increased.

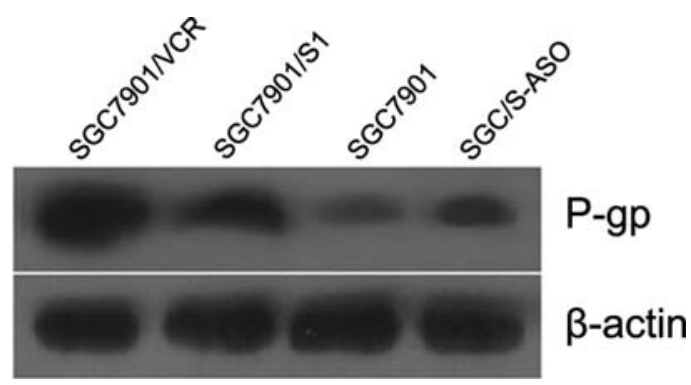

Figure 4. Western blot analysis of P-gp expression in SGC7901 cells $\beta$-actin was used as an internal control. The blot was visualized by enhanced chemiluminescence system. Representative of 3 independent experiments.

cells was $76.89 \%$ decreased. As expected, when the overexpression of sorcin in $\mathrm{SGC7} \mathrm{T} / \mathrm{S}_{1}$ cells was suppressed by sorcin ASO, the concentration of VCR was 3.48-fold increased (Table II).

Expression level of P-gp. To study the possible molecular mechanisms involved in sorcin-related MDR of gastric cancer, P-gp, a well-characterized drug transporter, was examined in SGC7901 cells. The relative expression level of P-gp to B-actin was markedly higher in SGC7901/S cells compared with empty vector transfected control cells and decreased in SGC7901/S $\mathrm{S}_{1}$-ASO cells (Fig. 4).

Partial reversal effects of verapamil on sorcin-related $M D R$. To further investigate the possible role of $\mathrm{P}$-gp in sorcin-related MDR, we examined whether resistance of SGC7901/S1 cells to drugs could be modulated by verapamil. The concentration $(<10 \mu \mathrm{g} / \mathrm{ml})$ of VRP alone did not cause any cytotoxicity effect on SGC7901/S $\mathrm{S}_{1}$ or SGC7901 cells. Inhibition of P-gp activity by VRP dramatically increased VCR cytotoxicity in sorcin-transfected SGC7901 cells. The reverse index was elevated as the concentration of VRP increased (Table III).

\section{Discussion}

In this study, we constructed a FLAG-sorcin fusion expression vector using gene-clone techniques. FLAG fusion proteins can be readily purified and assayed by ELISA or any other immunochemical detection method $(26,27)$. Thus, we chose this affinity system for further studies of sorcin protein characterization.

We carried out experiments to dissect out the effect of sorcin in drug resistant phenotype in gastric cancer cells by transfecting and overexpessing sorcin in non-resistant SGC7901 cells. The sorcin-transfected SGC7901 cells were 8.87-fold more resistant to VCR, and were crossresistant to several other chemotherapeutic agents (6.13fold ADM resistance, 6.67-fold Taxol resistance and 2.80fold 5-FU resistance). These results are in good agreement with those reported by Parekh et al (20), who demonstrated that sorcin DNA transfection into human ovarian and breast tumor cells resulted in low level of pacli-taxel resistance. Although the overexpression of sorcin did not produce high level of drug resistance, the result obtained present compelling evidence of the involvement of sorcin in developing MDR in gastric cancer cells. Further, we examined the effect of sorcin ASO on VCR sensitivity of sorcin-transfected SGC7901 cells. Sorcin ASO were employed to specifically inhibit sorcin expression in SGC7901-S $\mathrm{S}_{1}$ cells. Consistent with the activity in down-regulating the expression of sorcin protein, the sorcin ASO showed a

Table III. Reverse effection of VRP treatment in SGC7901 cells transfected with full-length sorcin cDNA.

\begin{tabular}{|c|c|c|c|c|}
\hline $\operatorname{VRP}(\mu \mathrm{g} / \mathrm{ml})$ & $\mathrm{VCR} \mathrm{IC}_{50}(\mu \mathrm{g} / \mathrm{ml}) \mathrm{SGC7901}$ & RI & $\mathrm{VCR} \mathrm{IC}_{50}(\mu \mathrm{g} / \mathrm{ml}) \mathrm{SGC} 7901 / \mathrm{S}_{1}$ & RI \\
\hline 0 & $0.51 \pm 0.13$ & - & $5.05 \pm 0.49$ & - \\
\hline 2.5 & $0.50 \pm 0.14$ & 1.02 & $4.17 \pm 0.33$ & 1.21 \\
\hline 5.0 & $0.46 \pm 0.09$ & 1.11 & $2.46 \pm 0.25$ & 2.05 \\
\hline 10 & $0.43 \pm 0.11$ & 1.19 & $1.19 \pm 0.21$ & 4.24 \\
\hline
\end{tabular}

The reversal effects of VRP on sorcin-mediated MDR were assessed using MTT assay. Sorcin transfectants and the parent SGC7901 cells were treated with different concentration of VCR accompanied by different concentration of VRP $(<10 \mu \mathrm{g} / \mathrm{ml})$. All values are presented as mean $\pm \mathrm{SD}$. Reverse index (RI) was defined as the $\mathrm{IC}_{50}$ value of cells in the absence of VRP/the $\mathrm{IC}_{50}$ value of cells in the presence of VRP. 
VCR-sensitization effect. The $\mathrm{IC}_{50}$ reduced to $1.30 \mu \mathrm{g} / \mathrm{ml}$ for the sorcin ASO-transfected SGC7901/S 1 cells, compared to that of 4.17 and $3.92 \mu \mathrm{g} / \mathrm{ml}$ for the scrambled ASO and oligofectamine transfected SGC7901/S 1 cells, respectively. These results, nevertheless, provide further support to the role that sorcin plays in the emergence of drug resistance.

An important question that arises is how does the overexpression of sorcin lead to the development of MDR in SGC7901 cells. In this study, we observed by the HPLC analysis that up-regulation of sorcin by sorcin-transfected in SGC7901 cells was accompanied with significantly decreased VCR accumulation. Consistent with this, SGC7901/ $\mathrm{S}_{1}$-ASO cells showed increased VCR accumulation. The results indicated that sorcin had a direct or indirect function of pumping drug out of cells. Transmembrane transport is known to be regulated by intracellular signals such as changes in the cytoplasmic free $\mathrm{Ca}^{2+}$ concentration $\left[\left(\mathrm{Ca}^{2+}\right) \mathrm{i}\right]$ (28). It has been speculated that $\mathrm{Ca}^{2+}$ may have a role in cytotoxic drug resistance (29). From a functional aspect, it is well known that sorcin is a calcium-binding protein. Sorcin can bind and thereby sequester up to $10 \%$ of the cytosolic calcium. The study of Bouchelouche et al, showed that the overproduction of sorcin protein in resistant cells may be related to the difference in the intracellular calcium, but calcium is not involved directly in drug transport processes and the level of $\mathrm{Ca}^{2+}$ itself has no influence on drug accumulation (30). Parekh et al (20) recently demonstrated that the role of sorcin in the development of paclitaxel resistance is distinct from its calcium-binding property.

The amplification of the gene that encodes sorcin is thought to be tightly associated with the amplification of the P-gp genes (31). Hirofumi et al (32) suggested that the overexpression of sorcin protein is not sufficient or a necessary condition for acquisition of the multidrug-resistant phenotype. However, to date, the contribution of sorcin to the MDR phenomenon has been questionable. Studies on VCR-resistant HOB1 lymphoma cell lines revealed that the sorcin gene was amplified upon exposure of parental HOB1 cells to a high concentration of VCR, and this phenomenon was not related to MDR1 gene amplification in the drugresistant cells $(22,23)$. Kawakami et al (24) reported that suppressing of MDR1 expression with siRNA did not change the expression level of sorcin mRNA, whereas the knockdown of sorcin induced up-regulation of MDR1 mRNA in HeLa cells. The mechanism of sorcin and its correlation with MDR1 might be different in different cancer cells.

P-gp, encoded by MDR1, is a multidrug efflux pump which reduce intracellular drug accumulation and/or alter intracellular drug compartmentalization. To clarify the association of P-gp with sorcin-related MDR, we investigated the effects of sorcin expression. The results showed that P-gp might mediate the sorcin-related MDR of SGC7901 cells. We further observed the effects of verapamil on sorcin-related MDR. The results of MTT assay showed that verapamil could partially reverse the VCR resistance in SGC7901-S 1 cells. Accordingly, HPLC analysis showed VRP increased the concentration of VCR in sorcintransfected SGC7901 cells, suggesting that regulation of $\mathrm{P}$-gp might be one of the mechanisms by which sorcin mediated MDR. However, verapamil only partially inhibited the MDR phenotype of SGC7901 cells, perhaps because the drug-resistant phenotype of the cells may be multifactorial.

To further study the mechanism of sorcin involved in mediating MDR, we will carry out a study on the interacting protein of sorcin protein using the FLAG protein expression and purification system.

In conclusion, our results in this study, further confirmed that sorcin plays an important role in the drug-resistant phenotype of gastric cancer cells. Sorcin may, therefore, represent a good target for developing more efficacious MDR reversal agents.

\section{Acknowledgements}

The authors would like to thank Professor Fan Daiming, Department of Gastroenterology, Xijing Hospital, Fourth Military Medical University, for his help with the SGC7901/ VCR cell line, and Dr Zeng Pingyao, Cancer research Institute, Central South University, for providing the eukaryotic expression vector pcDNA3.1-p53-FLAG and pcDNA3.1-FLAG.

\section{References}

1. Roder DM: The epidemiology of gastric cancer. Gastric Cancer 5 (Suppl. 1): 5-11, 2002.

2. Bae JM, Won YJ, Jung KW, Suh KA, Ahn DH and Park JG: Annual report of the Central Cancer Registry in Korea-1999: based on registered data from 128 hospitals. Cancer Res Treat 33: 367-372, 2001.

3. Kelley JR and Duggan JM: Gastric cancer epidemiology and risk factors. J Clin Epidemiol 56: 1-9, 2003.

4. Sun Xiudi, Mu Ren, Zhou Youshang, et al: Analysis of mortality rate of stomach cancer and its trend in twenty years in China. Chin J Oncol 26: 4-9, 2004.

5. Ferry DR, Teaunecker H and Kerr DJ: Clinical trials of P-glycoprotein reversal in solid tumours. Eur J Cancer 32: 1070-1081, 1996.

6. Fan K, Fan D, Cheng L and Li C: Expression of multidrug resistance related markers in gastric cancer. Anticancer Res 20: 4809-4814, 2000.

7. Takebayashi Y, Akiyama S, Natsugoe S, Hokita S, Niwa K, Kitazono M, Sumizawa T, Tani A, Furukawa T and Aikou T: The expression of multidrug resistance protein in human gastrointestinal tract carcinomas. Cancer 82: 661-666, 1998.

8. Oki E, Baba H, Tokunaga E, Nakamura T, Ueda N, Futatsugi M, Mashino K, Yamamoto M, Ikebe M, Kakeji Y and Maehara Y: Akt phosphorylation associates with LOH of PTEN and leads to chemoresistance for gastric cancer. Int J Cancer 117: 376-380, 2005.

9. Suzuki T, Yoshida K, Waka Y, Hamai Y, Sentani K, Que N and Yasui W: Melanoma-associated antigen-A1 expression predicts resistance to docetaxel and paclitaxel in advanced and recurrent gastric cancer. Oncol Rep 18: 329-336, 2007.

10. Cai XJ, Fan DM and Zhang XY: Establishment and biological characteristics of multidrug resistant gastric cancer cell line. J Chin Clin Cancer 54: 56-63, 1994.

11. Yang $\mathrm{L}$ and Zhu ZH: Reversal effect of VCR on resistance to vincristine in human multidrug-resistant gastric carcinoma cell line SGC7901/VCR. Chin J Dig 22: 112-113, 2002

12. Yang YX, Xiao ZQ, Chen ZC, Zhang GY, Yi H, Zhang PF, Li JL and Zhu G: Proteome analysis of multidrug resistance in vincristine-resistant human gastric cancer cell line SGC7901/ VCR. Proteomics 6: 2009-2021, 2006.

13. Yi H, Yang YX, Tang CE, Chen ZC, Zhang GY and Xiao ZQ: Sorcin overexpression and multidrug resistance in human gastric cancer cells. Zhong Nan Da Xue Xue Bao Yi Xue Ban 31: 340-344, 349, 2006.

14. Meyers MB and Biedler JL: Increased synthesis of a low molecular weight protein in vincristine-resistant cells. Biochem Biophys Res Commun 99: 228-235, 1981. 
15. Yokota T, Kouno J, Adachi k, Takahashi H, Matsumoto K, Sugisaki Y, Onda M and Tsunoda T: Identification of histological markers for malignant glioma by genome-wide expression analysis: dynein, alpha-PIX and sorcin. Acta Neuropathol 111: $29-38,2006$.

16. Wood RJ, Tchack L, Angelo G, Pratt RE and Sonna LA: DNA microarray analysis of vitamin D-induced gene expression in a human colon carcinoma cell line. Physiol Genomics 17: 122-129, 2004.

17. Beyer-Sehlmeyer G, Hiddemann W, Wormann B and Bertram J: Suppressive substractive hybridisation reveals differential expression of serglycin, sorcin, bone marrow proteglycan and prostate-tumour-inducing gene I (PTI-1) in drug-resistant and sensitive tumour cell lines of haematopoietic origin. Eur J Cancer 35: 1735-1742, 1999.

18. Padar S, van Breemen C, Thomas DW, Uchizono JA, Livesey JC and Rahimian R: Differential regulation of calcium homeostasis in adenocarcinoma cell line A549 and its Taxol-resistant subclone. Br J Pharmacol 142: 305-316, 2004.

19. Tan Y, Li G, Zhao C, Wang J, Zhao H, Xue Y, Han M and Yang C: Expression of sorcin predicts poor outcome in acute myeloid leukemia. Leuk Res 27: 125-131, 2003.

20. Parekh HK, Deng HB, Choudhary K, Houser SR and Simpkins H: Overexpression of sorcin, a calcium-binding protein, induces a low level of paclitaxel resistance in human ovarian and breast cancer cells. Biochem Pharmacol 63: 1149-1158, 2002.

21. Van der Blick AM, Baas F, Van der Velde-Koerts T, Biedler JL, Meyers MB, Ozols RF, Hamilton TC, Joenje H and Borst P: Genes amplified and overexpressed in human multidrugresistant cell lines. Cancer Res 48: 5927-5932, 1988.

22. Wang SL, Tam MF, Ho YS, Pai SH and Kao MC: Isolation and molecular cloning of human sorcin, a calcium-binding protein in vinscritine-resistant HOB 1 lymphoma cell lines. Biochem Biophys Acta 1260: 285-293, 1995.
23. Lee WP: Purification, cDNA cloning and expression of human sorcin in vincristine resistant HOB1 lymphoma cell line. J Arch Biochem Biophys 325: 217-226, 1996.

24. Kawakami M, Nakamura T, Okamura N, Komoto C, Narkova S, Kobayashi H, Hashimoto N, Okumura K and Sakaeda T: Knock-down of sorcin Induces up-regulation of MDR1 in HeLa cells. Biol Pharm Bull 30: 1065-1073, 2007.

25. Zhou Y, Xu YF, Tan YH, Qi J, Xiao Y, Yang CZ, Zhu ZP and Xiong DS: Sorcin, an important gene associated with multidrugresistance in human leukemia cells. Leuk Res 30: 469-476, 2006.

26. Hopp TP, Gallis B and Prickett KS: A short polypeptide marker sequence useful for recombinant protein identification and purification. Bior Technology 6: 1204-1210, 1988.

27. Einhauer A and Jungbauer A: The FLAG peptide, a versatile fusion tag for the purification of recombinant proteins. J Biochem Biophys Methods 49: 455-465, 2001.

28. Rasmussen $\mathrm{H}$ and Barrett PQ: Calcium messenger system: an integrated view. Physiol Rev 64: 938-984, 1984.

29. Beck WT: The cell biology of multidrug resistance. Biochem Pharmacol 36: 2879-2887, 1987.

30. Bouchelouche P, Friche E, Sehested M, Jensen PB and Skovsgaard T: Cytosolic free $\mathrm{Ca}^{2+}$ in daunorubicin and vincristine resistant Ehrlich ascites tumor cells. Drug accumulation is independent of intracellular $\mathrm{Ca}^{2+}$ changes. Biochem Pharmacol 41: 243-253, 1991.

31. Van der Bliek AM, Meyers MB, Biedler JL, Hes E and Borst PA: 22-kD protein (sorcin:V19) encoded by an amplified gene in multidrug-resistant cells, is homologous to the calcium-binding light chain of calpain. EMBO J 5: 3201-3208, 1986.

32. Hirofumi $\mathrm{H}$, Etsuko $\mathrm{O}$, Tomoko $\mathrm{OH}$ and Takashi $\mathrm{T}$ : Purification of the Mr 2200 calcium-binding protein (sorcin) associated with multidrug resistance and its detection with monoclonal antibodies. Cancer Res 48: 3173-3178, 1988. 